\title{
Novilhas Alimentadas com Bagaço de Cana-de-Açúcar Tratado com Amônia Anidra e, ou, Sulfeto de Sódio ${ }^{1}$
}

\author{
Aureliano José Vieira Pires ${ }^{2}$, Rasmo Garcia $^{3}$, Sebastião de Campos Valadares Filho ${ }^{3}$, Odilon \\ Gomes Pereira ${ }^{3}$, Paulo Roberto Cecon ${ }^{4}$, Fabiano Ferreira da Silva ${ }^{5}$, Polyana Albino Silva ${ }^{6}$, \\ Cristina Mattos Veloso 5
}

\begin{abstract}
RESUMO - Foram utilizadas 16 novilhas $1 \frac{1}{2}$ Holandês/Indubrasil, com peso vivo médio de 230 kg, alojadas em baias individuais cobertas, distribuídas em um delineamento inteiramente casualisado, com quatro tratamentos e quatro repetições, definidos conforme a alimentação: T1 - Bagaço sem tratamento (controle); T2 - Bagaço tratado com 2,5\% de $\mathrm{Na}_{2} \mathrm{~S}$; T3 - Bagaço tratado com $4 \%$ de $\mathrm{NH}_{3} \mathrm{e}$ T4 - Bagaço tratado com 2,5\% de $\mathrm{Na}_{2} \mathrm{~S}+4 \%$ de $\mathrm{NH}_{3}$. Todos tratamentos foram feitos com base na matéria seca do bagaço. O bagaço de cana-de-açúcar ficou armazenado por 10 meses e, após a abertura dos silos, foi fornecido aos animais ad libitum, pela manhã (7 h), para obter sobras em torno de 10\%, e todos animais receberam 3,5 kg/cabeça/dia de concentrado contendo 19\% de proteína bruta. Verificou-se efeito para ganho de peso diário e total, observando-se ganhos maiores para os tratamentos com $\mathrm{NH}_{3}$. Os valores médios encontrados para ganho de peso diário foram 702, 684, 1026 e $1005 \mathrm{~g} / \mathrm{cab}$, respectivamente, para o bagaço sem tratamento, tratado com $\mathrm{Na}_{2} \mathrm{~S}$, tratado com $\mathrm{NH}_{3}$ e tratado com $\mathrm{NH}_{3}$ mais $\mathrm{Na}_{2} \mathrm{~S}$. O consumo de $\mathrm{MS}$, em função do peso vivo, variou de 1,92 (controle) a 2,46\% PV ( $\mathrm{NH}_{3}$ ), enquanto o consumo de FDN variou de 0,84 (controle) a 1,14\% PV $\left(\mathrm{NH}_{3}\right)$.
\end{abstract}

Palavras-chave: amonização, bagaço, resíduo

\section{Diets with of Sugarcane Bagasse Treated with Anhydrous Ammonia and/or Sodium Sulfate Fed Heifers}

\begin{abstract}
Sixteen $1 \frac{1}{2}$ Holstein/Indubrasil heifers, averaging $230 \mathrm{~kg}$ of live weight, housed in individual boxes, were allotted to a completely randomized design, with four treatments and four replicates, according to the following treatments: T1 - bagasse without treatment (control); T2 - bagasse treated with $2.5 \% \mathrm{Na}_{2} \mathrm{~S}$; T3 - bagasse treated with $4 \% \mathrm{NH}_{3}$ and $\mathrm{T} 4$ - bagasse treated with $2.5 \% \mathrm{Na}_{2} \mathrm{~S}$ $+4 \% \mathrm{NH}_{3}$. All treatments were based on bagasse dry matter. Sugarcane bagasse was stored for 10 months e, after silo opening, animals were ad libitum fed, in the morning ( 7 a.m.), to obtain orts of approximately $10 \%$, and all animals were fed $3.5 \mathrm{~kg} / \mathrm{head} / \mathrm{day}$ of concentrate with $19 \%$ crude protein. It was verified effect for daily and total weight gain, and the higher gains were observed for the treatments with $\mathrm{NH}_{3}$. The average values observed for daily weight gain were of 702, 684, 1026, and $1005 \mathrm{~g} /$ head, respectively, for the bagasse without treatment, treated with $\mathrm{Na}_{2} \mathrm{~S}$, treated with $\mathrm{NH}_{3}$ and treated with $\mathrm{NH}_{3}$ plus $\mathrm{Na}_{2} \mathrm{~S}$. DM intake, as a function of live weight, ranged form 1.92 (control) to $2.46 \% \mathrm{LW}\left(\mathrm{NH}_{3}\right)$ and NDF intake ranged from 0.84 (control) to $1.14 \% \mathrm{LW}\left(\mathrm{NH}_{3}\right)$.
\end{abstract}

Key Words: ammoniation, bagasse, residue

\section{Introdução}

Subprodutos agro-industriais, resíduos de culturas anuais de inverno e verão, fenos de plantas colhidas no estádio de maturação avançado e forragens resultantes da colheita de sementes de gramíneas e leguminosas podem ser considerados alternativas para a suplementação animal no período de escassez de forragens.
Deve-se considerar que esses volumosos são de baixa qualidade, pois apresentam alto conteúdo de parede celular (acima de 60\%), elevado teor de fibra em detergente ácido (acima de $40 \%$ ) e reduzidos conteúdos de proteína bruta (abaixo de 6\%), além da baixa digestibilidade da matéria seca (40 a 50\%), o que resulta em baixos níveis de consumo voluntário (Reis \& Rodrigues, 1993).

Entre os vários subprodutos existentes no momento,

\footnotetext{
${ }_{1}^{1}$ Parte da tese de Doutorado do primeiro autor, DZO/UFV, Viçosa, MG.

2 Professor Adjunto DTRA/UESB, Itapetinga, BA, Pós-doutorando Bolsista da FAPESB. E.mail: aureliano@uesb.br

${ }^{3}$ Pesquisador do CNPq, DZO/UFV, Viçosa, MG.

${ }^{4}$ Professor DPI/UFV, Viçosa, MG.

5 Professor Adjunto DTRA/UESB, Itapetinga, BA.

${ }^{6}$ Estudante do Programa de Mestrado em Zootecnia UFV, Viçosa, MG.
} 
o bagaço de cana-de-açúcar merece destaque, em razão de serem produzidas, anualmente no país, cerca de 75 milhões de toneladas por ano (Bürgi, 1995). Este bagaço proveniente de usinas de açúcar, álcool ou aguardente constitui um problema, por ser pouco utilizado, sendo muitas vezes queimado ao ar livre, enquanto poderia ser usado na alimentação de ruminantes.

A amônia anidra é o nome químico dado ao composto que apresenta um átomo de nitrogênio e três de hidrogênio $\left(\mathrm{NH}_{3}\right)$. Possui elevado teor de nitrogênio (82\%) e, normalmente, é obtida no estado líquido sob baixas temperaturas ou pressões relativamente altas. A uréia $\left(\mathrm{NH}_{2} \mathrm{CONH}{ }_{2}\right)$, que, por sua vez, possui, em média, $44 \%$ de nitrogênio, é encontrada na forma sólida e necessita de umidade e presença da enzima urease para que possa produzir $2 \mathrm{NH}_{3}+\mathrm{CO}_{2}$, para cada molécula de uréia.

Um dos efeitos da ação da amônia sobre a forragem é a desestruturação no complexo formado pelos componentes da fibra (celulose, hemicelulose e lignina), oferecendo aos microrganismos maior área de exposição e, conseqüentemente, aumentando o grau de utilização das diferentes frações da fibra. Outro efeito marcante da amonização é o incremento no teor dos compostos nitrogenados, que, normalmente, é baixo, o que limita o crescimento dos microrganismos do rúmen (Garcia \& Neiva, 1994).

Trabalhos têm mostrado que melhores resultados com amonização têm sido relatados em forragens com baixa qualidade, ou seja, menos de $6 \%$ de proteína bruta (PB) e $48 \%$ de nutrientes digestíveis totais (NDT), valores encontrados na maioria dos subprodutos agro-industriais e restos de culturas (Castrillo, et al., 1995; Fike, et al., 1995; Oliveira, et al., 1994).

Goonewardene et al. (1998), utilizando cevada (planta toda) amonizada ou não (1\% base MS) na alimentação de novilhos com peso médio de $284 \mathrm{~kg}$, não observaram diferenças no ganho de peso diário e na ingestão de matéria seca para os tratamentos. O ganho médio diário foi de 1,11 e 1,18 kg/dia e a ingestão diária, de 8,5 e 8,3kg/dia, respectivamente, para a cevada não-amonizada e amonizada. Cabe ressaltar que a dose utilizada de amônia (1\% base MS), normalmente, não é suficiente para alterar o valor nutritivo de forragens, principalmente em forragens que já possuem bom valor nutritivo.

Em um estudo utilizando cabras em lactação recebendo dietas à base de palha de Schizachyrium exile sem tratamento, ou tratada com uréia (5 kg de uréia em $50 \mathrm{~L}$ de água para $100 \mathrm{~kg}$ de palha), e palha sem tratamento mais $400 \mathrm{~g}$ de caroço de algodão, Djibrillou et al. (1998) verificaram maior produção de leite nos animais que receberam palha tratada (443 g/dia) e palha sem tratamento mais suplementação (447 g/dia), enquanto as cabras do tratamento controle apresentaram $389 \mathrm{~g} /$ dia.

Neiva et al. (1998), avaliando o desempenho de novilhos de corte alimentados com dietas à base de silagens de milho (contendo 35 e $45 \%$ de MS) tratadas com 1,2\% de $\mathrm{NH}_{3}$ (base da MS) e rolão de milho tratado com 2,4\% de $\mathrm{NH}_{3}$ (base da MS), não observaram diferença no consumo de matéria seca, em função do peso metabólico e do peso vivo. Apesar de não encontrarem diferença $(P>0,05)$, observaram tendência de maior ganho de peso para os animais que consumiram silagem de milho com $35 \%$ de MS (1,167 kg/dia, quando não-amonizada, e 1,045 kg/dia, quando amonizada), seguida da silagem com $45 \%$ de MS (0,945 kg/dia, quando não-amonizada, e 0,900 kg/dia, quando amonizada) e, por último, do rolão de milho $(0,727 \mathrm{~kg} /$ dia, quando não-amonizado, e 0,950 kg/dia, quando amonizado). Estes resultados podem ser atribuídos aos baixos níveis de amônia anidra adicionada às silagens $(1,2 \%)$ e ao bom valor nutritivo.

Fike et al. (1995) utilizaram palhada de trigo amonizada (3\% de $\mathrm{NH}_{3}$ base MS) como volumoso para vacas de corte, e suplementação concentrada com os seguintes tratamentos: controle (sem suplementação), suplementação com 2,0 kg de concentrado contendo $12 \%$ de $\mathrm{PB}$, suplementação com $2,0 \mathrm{~kg}$ de concentrado contendo $20,1 \%$ de PB e suplementação com 2,0 kg de concentrado contendo $31,7 \%$ de PB. Verificaram crescente ganho de peso e melhor condição corporal, à medida que se aumentou a proteína do concentrado. Todavia, não foi observada perda de peso para os animais sem suplementação concentrada recebendo apenas palha de trigo amonizada. Os autores relataram ainda que o peso médio de bezerros ao nascimento e o peso à desmama não foram afetados pelos tratamentos, o que também foi observado para taxa de prenhez durante a estação de monta.

Aumento no consumo de MS total de 30,2 para $50,6 \mathrm{gMS} / \mathrm{kg}^{0,75}$, respectivamente, para o material sem tratamento e o tratado com amônia, e acréscimo no consumo de palha (551 e 858 g/dia, respectivamente) foram relatados por Castrillo et al. (1995), em um experimento com ovinos alimentados com palha de cevada sem tratamento ou tratada com amônia anidra (3\% base MS).

\section{R. Bras. Zootec., v.33, n.4, p.1078-1085, 2004}


Rahal et al. (1997), utilizando palhada de arroz sem tratamento ou tratada com 3\% de uréia em dietas para novilhas com peso médio de $106 \mathrm{~kg}$, verificaram ingestão de matéria orgânica degradável de 2,1 e 2,6\% PV, respectivamente.

Fahmy \& Klopfenstein (1994) utilizaram silagem de milho contendo $40 \%$ de MS, em três tratamentos: 1) silagem de milho, 2) silagem de milho com $6,6 \%$ de uréia e 3) silagem de milho com 6,6\% de uréia mais $5 \%$ de $\mathrm{SO}_{2}$ em forma gasosa. Os teores de proteína encontrados para os tratamentos 1 , 2 e 3 foram de 5,2; 13,4 ; e $17,1 \%$, respectivamente. Verificaram-se, portanto, aumentos de 156,3 e $226,7 \%$ de proteína bruta para os tratamentos com uréia e uréia mais $\mathrm{SO}_{2}$, quando comparados ao controle, o que comprova a eficiência da adição de enxofre na retenção de nitrogênio no volumoso tratado com fontes de nitrogênio não-protéico.

Objetivou-se, com este trabalho, avaliar o valor nutritivo do bagaço de cana-de-açúcar tratado com amônia e, ou, sulfeto de sódio, verificando a conservação, a composição químico-bromatológica e o desempenho de novilhas $1 \frac{1}{2}$ sangue Holandês-Indubrasil.

\section{Material e Métodos}

O experimento foi conduzido na Fazenda Córrego Novo, na cidade de Santa Cruz do Escalvado, e no Departamento de Zootecnia da Universidade Federal de Viçosa, Minas Gerais, utilizando bagaço de canade-açúcar contendo $50 \%$ de MS, proveniente da moagem para fabricação de aguardente.

Foram utilizadas 16 novilhas $1 / 2$ Holandês/ Indubrasil, com peso vivo médio de $230 \mathrm{~kg}$, alojadas em baias individuais cobertas e calçadas, distribuídas em um delineamento inteiramente casualisado, com quatro tratamentos e quatro repetições, definidos conforme a alimentação:

T1 - Bagaço sem tratamento (armazenado em local coberto)

T2 - Bagaço tratado com 2,5\% de $\mathrm{Na}_{2} \mathrm{~S}$

T3 - Bagaço tratado com $4 \%$ de $\mathrm{NH}_{3}{ }^{2}$

T4 - Bagaço tratado com 2,5\% de $\mathrm{Na}_{2} \mathrm{~S}+4 \%$ de $\mathrm{NH}_{3}$

Todas as novilhas receberam diariamente $3,5 \mathrm{~kg}$ de ração concentrada (contendo 19\% de PB, base MS), sendo 2 kg pela manhã (7 h) e 1,5 kg à tarde (15 h). A proporção de ingredientes é mostrada na Tabela 1 e a composição químico-bromatológica, na Tabela 2.

Todos tratamentos foram feitos com base na matéria seca do bagaço de cana-de-açúcar, e para o tratamento com $\mathrm{Na}_{2} \mathrm{~S}$, este foi diluído na proporção de 3:1 água:produto. Três silos de superfície com cerca de quatro toneladas de bagaço de cana-deaçúcar foram confeccionados, utilizando-se lona plástica no solo e na cobertura dos silos.

Para a aplicação da amônia anidra, utilizou-se um botijão com capacidade de 80 kg de amônia; a quantidade necessária a ser adicionada foi obtida por diferença de peso do botijão, à medida que se aplicava a amônia. A amônia anidra foi aplicada em dois pontos opostos de cada silo, de maneira que permitisse melhor difusão em todo o material ensilado. Utilizaram-se canos PVC de 1/2” perfurados a cada $20 \mathrm{~cm}$, com diâmetro de $0,5 \mathrm{~cm}$, tendo uma de suas extremidades vedadas.

O bagaço de cana-de-açúcar ficou armazenado por 10 meses e, após a abertura dos silos, foi fornecido aos animais ad libitum, pela manhã $(7 \mathrm{~h})$, de forma a sobrar em torno de $10 \%$, sendo diariamente pesado. A composição químico-bromatológica do bagaço de cana-de-açúcar antes de ser tratado pode ser verificada na Tabela 3.

O experimento teve 19 dias de adaptação, nos quais os animais foram vermifugados, e as pesagens foram efetuadas em três períodos de 21, 21 e 15 dias, respectivamente, sendo no início e no final do experimento, as pesagens foram efetuadas após jejum de 15 horas. Devido à grande perda do material tratado somente com sulfeto, a última pesagem foi realizada apenas com 15 dias, totalizando então 76 dias.

Após coletas semanais, as amostras de volumoso e sobras foram pesadas, acondicionadas em freezer, posteriormente congeladas e liofilizadas, para evitar perdas de nitrogênio, processadas em moinho tipo Willey, com peneira de 20 mesh, e submetidas às análises de nitrogênio total (NT), fibra em detergente neutro (FDN), fibra em detergente ácido (FDA), celulose, hemicelulose e lignina, segundo Silva (1990).

Foram avaliados os consumos de MS, FDN e PB, expressos em kg/dia, porcentagem do peso vivo e $\mathrm{g} / \mathrm{kg}^{0,75}$, bem como os ganhos de peso e a conversão alimentar, e os resultados foram interpretados estatisticamente por intermédio da análise de variância e do teste Tukey, a 5\% de probabilidade, utilizando-se o Sistema de Análises Estatísticas e Genéticas, SAEG versão 8.0 (UFV, 1998). 


\section{Resultados e Discussão}

Devido à grande perda do material tratado somente com sulfeto, o experimento não durou o período estabelecido. Entretanto, o material que apresentava fungos foi retirado, fornecendo-se somente aquele que não apresentava sinais visíveis de fungos. Para o silo que não recebeu qualquer tratamento, o material apresentou-se quase em sua totalidade perdido, tornando-se necessário, após 10 meses, que seria o início do experimento, adquirir novamente bagaço in natura para corresponder ao tratamento controle. Este bagaço apresentou alto teor de matéria seca e ficou armazenado em ambiente coberto, livre de chuvas ou de sol. O bagaço nos silos que receberam o tratamento com amônia anidra não apresentou sinais visíveis de fungos.

A composição químico-bromatológica do bagaço com os respectivos tratamentos testemunha, $\mathrm{Na}_{2} \mathrm{~S}$, $\mathrm{NH}_{3}$, e $\mathrm{NH}_{3}$ mais $\mathrm{Na}_{2} \mathrm{~S}$ podem ser observados na Tabela 4. Verifica-se que a adição de $\mathrm{Na}_{2} \mathrm{~S}$ praticamente não alterou a composição nem a DIVMS. Entretanto, para os tratamentos onde se utilizou $\mathrm{NH}_{3}$, observam-se aumento da PB e da DIVMS, redução da FDN e da hemicelulose e menores variações nos valores de FDA e celulose. Com base nestes resultados, pode-se verificar a eficiência da $\mathrm{NH}_{3}$ (dose de $4 \%$ base MS) no tratamento do bagaço de cana-de-açúcar.

Tabela 1 - Proporção dos ingredientes na ração concentrada, expressa na base da matéria seca

Table 1 - Proportion of ingredients in concentrated ration, expressed in base dry matter

\begin{tabular}{lc}
\hline $\begin{array}{l}\text { Ingredientes } \\
\text { Feedstuffs }\end{array}$ & $\begin{array}{c}\text { Porcentagem } \\
\text { Percentage }\end{array}$ \\
\hline $\begin{array}{l}\text { Farelo de soja } \\
\text { Soybean meal }\end{array}$ & 30 \\
$\begin{array}{l}\text { Milho } \\
\text { Corn }\end{array}$ & 66 \\
Suplemento mineral* \\
$\begin{array}{l}\text { Mineral supplement* } \\
\text { NaCl }\end{array}$ & 3 \\
\hline Total & 1 \\
\hline
\end{tabular}

* Composição por kg: $205 \mathrm{~g}$ de cálcio, $150 \mathrm{~g}$ de fósforo, $48 \mathrm{~g}$ de enxofre, $30 \mathrm{~g}$ de magnésio, $720 \mathrm{mg}$ de zinco, $150 \mathrm{mg}$ de cobre, $256 \mathrm{mg}$ manganês, $220 \mathrm{mg}$ de iodeto de potássio, $160 \mathrm{mg}$ de cobalto e $55 \mathrm{mg}$ de selenito de sódio.

* Composition for $\mathrm{kg}: 205 \mathrm{~g}$ calcium, $150 \mathrm{~g}$ phosphorus, $48 \mathrm{~g}$ sulfur, $30 \mathrm{~g}$ magnesium, $720 \mathrm{mg}$ zinc, $150 \mathrm{mg}$ copper, $256 \mathrm{mg}$ manganese, $220 \mathrm{mg}$ potassium iodate, $160 \mathrm{mg}$ cobalt, $55 \mathrm{mg}$ sodium selenite.
Verificou-se efeito $(\mathrm{P}<0,01)$ para ganho de peso diário e total, observando-se maiores ganhos para os tratamentos com $\mathrm{NH}_{3}$ (Tabela 5). Os valores médios

Tabela 2 - Composição químico-bromatológica da ração concentrada

Table 2 - Composition chemical-bromatologic of concentrate ration

\begin{tabular}{|c|c|}
\hline $\begin{array}{l}\text { Itens } \\
\text { Items }\end{array}$ & $\begin{array}{l}\text { Porcentagem } \\
\text { Percentage }\end{array}$ \\
\hline Matéria seca & 87,0 \\
\hline Dry matter & \\
\hline Nutrientes digestíveis totais (NDT) $^{1}$ & 80,0 \\
\hline Total digestible nutients (TDN) & \\
\hline Proteína bruta $(\mathrm{PB})^{1}$ & 19,0 \\
\hline Crude protein $(C P)$ & \\
\hline $\begin{array}{l}\text { Fibra em detergente neutro (FDN) }{ }^{1} \\
\text { Neutral detergent fiber (NDF) }\end{array}$ & 12,0 \\
\hline $\begin{array}{l}\text { Fibra em detergente ácido(FDA })^{1} \\
\text { Acid detergent fiber }(A D F)\end{array}$ & 6,5 \\
\hline $\begin{array}{l}\text { Hemicelulose } \\
\text { Hemicellulose }\end{array}$ & 5,5 \\
\hline $\begin{array}{l}\text { Celulose }{ }^{1} \\
\text { Cellulose }\end{array}$ & 3,5 \\
\hline $\begin{array}{l}\text { Lignina }^{1} \\
\text { Lignin }^{-1}\end{array}$ & 1,8 \\
\hline
\end{tabular}

${ }^{1}$ Base da matéria seca.

${ }^{1}$ Dry matter basis.

Tabela 3 - Nutrientes e digestibilidade in vitro da matéria seca (DIVMS) do bagaço de cana-de-açúcar antes do tratamento

Table 3 - Nutrients and in vitro dry matter digestibility (IVDMD) of sugarcane bagasse before treatment

\begin{tabular}{|c|c|}
\hline $\begin{array}{l}\text { Nutrientes } \\
\text { Nutrients }\end{array}$ & $\begin{array}{l}\text { Porcentagem } \\
\text { Percentage }\end{array}$ \\
\hline Matéria seca & 50,0 \\
\hline Dry matter & \\
\hline Proteína bruta $(\mathrm{PB})^{1}$ & 1,8 \\
\hline Crude protein & \\
\hline $\begin{array}{l}\text { Fibra em detergente neutro (FDN) }{ }^{1} \\
\text { Neutral detergent fiber (NDF) }\end{array}$ & 94,3 \\
\hline $\begin{array}{l}\text { Fibra em detergente ácido (FDA) }{ }^{1} \\
\text { Acid detergent fiber (ADF) }\end{array}$ & 62,7 \\
\hline $\begin{array}{l}\text { Hemicelulose } \\
\text { Hemicellulose }\end{array}$ & 31,6 \\
\hline $\begin{array}{l}\text { Celulose } \\
\text { Cellulose }\end{array}$ & 45,3 \\
\hline $\begin{array}{l}\text { Lignina } \\
\text { Lignin }\end{array}$ & 16,5 \\
\hline $\begin{array}{l}\text { DIVMS } \\
\text { IVDMD }\end{array}$ & 31,8 \\
\hline
\end{tabular}

${ }^{1}$ Base da matéria seca.

${ }^{1}$ Dry matter basis.

R. Bras. Zootec., v.33, n.4, p.1078-1085, 2004 
encontrados para ganho de peso no período foram de 40,0; 39,0; 58,5; e 57,3 kg e para ganho de peso diário, 702, 684, 1026 e $1005 \mathrm{~g} / \mathrm{cab}$, respectivamente, para o bagaço sem tratamento, tratado com $\mathrm{Na}_{2} \mathrm{~S}$, tratado com $\mathrm{NH}_{3}$ e tratado com $\mathrm{NH}_{3}$ mais $\mathrm{Na}_{2} \mathrm{~S}$.

Por sua vez, a conversão alimentar não foi influenciada pelos tratamentos, registrando-se valores de 7,$26 ; 7,73 ; 6,69$; e 6,33 , respectivamente, para os tratamentos testemunha, $\mathrm{Na}_{2} \mathrm{~S}, \mathrm{NH}_{3}$ e $\mathrm{NH}_{3}$ mais $\mathrm{Na}_{2} \mathrm{~S}$. Apesar de não ter sido constatada diferença significativa, verificou-se tendência de menores valores para conversão alimentar, quando os animais foram alimentados com bagaço tratado com $\mathrm{NH}_{3}$ (Tabela 5).

Segundo o NRC (1989), a exigência diária para uma novilha em crescimento com peso vivo de $250 \mathrm{~kg}$ é de 5,65 kg de MS, 3,7 kg de NDT e $678 \mathrm{~g}$ de proteína bruta. Verifica-se, portanto, que no presente trabalho os tratamentos controle e sulfeto apresentaram consumo de MS/dia inferior (Tabela 5) e de proteína

Tabela 4 - Valores médios de proteína bruta (PB), fibra em detergente neutro (FDN) da fibra em detergente ácido (FDA), hemicelulose, celulose e lignina e da digestibilidade in vitro da matéria seca (DIVMS) do bagaço de cana-de-açúcar tratado ou não com amônia anidra $\left(\mathrm{NH}_{3}\right)$ e, $\mathrm{ou}$, sulfeto de sódio $\left(\mathrm{Na}_{2} \mathrm{~S}\right)$

Table 4 - Medium values of crude protein (CP), neutral detergent fiber (NDF), acid detergent fiber (ADF), hemicellulose, cellulose, lignin and in vitro dry matter digestibility (IVDMD) of sugarcane bagasse treated or not with anhydrous ammonia $\left(\mathrm{NH}_{3}\right)$ and, or, sodium sulphide $\left(\mathrm{Na}_{2} \mathrm{~S}\right)$

\begin{tabular}{|c|c|c|c|c|}
\hline \multirow[t]{2}{*}{$\begin{array}{l}\text { Itens } \\
\text { Items }\end{array}$} & \multicolumn{4}{|c|}{$\begin{array}{c}\text { Tratamento } \\
\text { Treatment }\end{array}$} \\
\hline & $\begin{array}{l}\text { Controle } \\
\text { Control }\end{array}$ & $\mathrm{Na}_{2} \mathrm{~S}$ & $\mathrm{NH}_{3}$ & $\mathrm{Na}_{2} \mathrm{~S}+\mathrm{NH}_{3}$ \\
\hline $\begin{array}{l}\mathrm{PB}^{1} \\
\mathrm{CP}\end{array}$ & 1,8 & 2,6 & 16,9 & 19,0 \\
\hline $\begin{array}{l}\mathrm{FDN}^{1} \\
N D F\end{array}$ & 94,7 & 93,4 & 75,8 & 78,7 \\
\hline $\begin{array}{l}\mathrm{FDA}^{1} \\
A D F\end{array}$ & 61,5 & 63,5 & 56,4 & 58,8 \\
\hline $\begin{array}{l}\text { Hemicelulose }^{1} \\
\text { Hemicellulose }\end{array}$ & 33,1 & 29,9 & 19,4 & 19,9 \\
\hline $\begin{array}{l}\text { Celulose }^{1} \\
\text { Cellulose }\end{array}$ & 44,8 & 44,3 & 40,8 & 42,2 \\
\hline $\begin{array}{l}\text { Lignina }^{1} \\
\text { Lignin }\end{array}$ & 15,2 & 17,9 & 13,5 & 14,6 \\
\hline $\begin{array}{l}\text { DIVMS } \\
\text { IVDMD }\end{array}$ & 32,1 & 32,9 & 59,8 & 58,1 \\
\hline
\end{tabular}

${ }^{1}$ Base da matéria seca.

${ }^{1}$ Dry matter basis.

R. Bras. Zootec., v.33, n.4, p.1078-1085, 2004 bruta/dia semelhante (Tabela 6) aos apresentados pelo NRC (1989).

Resultados semelhantes foram encontrados por Oliveira et al. (1994), ao fornecerem palha de arroz tratada com $3 \%$ de $\mathrm{NH}_{3}$ (base MS) e $4 \mathrm{~kg}$ de concentrado/dia a novilhos com peso médio de $232 \mathrm{~kg}$. Os autores registraram ganhos diários de 570 e 990 g para os animais que receberam a palha de arroz nãoamonizada e tratada com $\mathrm{NH}_{3}$, respectivamente. Valores de 12,39 e 9,49 para a conversão alimentar foram verificados pelos autores para os animais que consumiram palha não-amonizada e palha amonizada, respectivamente. Estes dados para conversão alimentar foram superiores aos encontrados no presente trabalho, entretanto, a DIVMS da palha de arroz apresentou valores de 24,47 e 32,33 para os respectivos tratamentos.

Verificou-se efeito também $(\mathrm{P}<0,01)$ para consumo de MS/dia, consumo de volumoso em kg/dia, consumo de MS em \% do peso vivo e consumo de MS, em função do peso metabólico (gMS/ $\mathrm{kg}^{0,75}$ ) (Tabela 5). $\mathrm{O}$ consumo de MS em $\mathrm{kg} / \mathrm{dia}$ foi maior para os animais que receberam bagaço tratado com $\mathrm{NH}_{3}$ $(6,81 \mathrm{~kg} / \mathrm{dia})$ e tratado com $\mathrm{NH}_{3}$ mais $\mathrm{Na}_{2} \mathrm{~S}(6,38 \mathrm{~kg} /$ dia). Observou-se maior consumo de bagaço tratado com $\mathrm{Na}_{2} \mathrm{~S}(5,24 \mathrm{~kg} / \mathrm{dia})$ que o tratamento controle $(4,85 \mathrm{~kg} / \mathrm{dia})$. O bagaço do tratamento controle foi fornecido com teor de MS superior a $80 \%$, permitindo aos animais selecionarem a dieta, comparado ao material com teor de umidade mais elevado (50\%). Fato semelhante foi verificado para consumo diário de volumoso, no qual foram encontrados valores de 1,81; 2,44; 3,77; e 3,34 kg/cab para os respectivos tratamentos controle, $\mathrm{Na}_{2} \mathrm{~S}, \mathrm{NH}_{3}$ e $\mathrm{NH}_{3}$ mais $\mathrm{Na}_{2} \mathrm{~S}$.

$\mathrm{O}$ consumo de $\mathrm{MS}$, em função do peso vivo, que variou de 1,92 (controle) a 2,46\% PV ( $\mathrm{NH}_{3}$ ), diferiu entre as rações (Tabela 5). O aumento no consumo total de MS foi, em média, 27\% superior ao controle, o que resultou também em maior ganho de peso.

O consumo de MS, em função do peso metabólico, acompanhou da mesma forma o consumo de MS, em função do peso vivo. Os valores encontrados foram de 76,72; 82,46; 100,18; e 97,44 gMS/ $\mathrm{kg}^{0,75}$, para os respectivos tratamentos controle, $\mathrm{Na}_{2} \mathrm{~S}, \mathrm{NH}_{3}$ e $\mathrm{NH}_{3}$ mais $\mathrm{Na}_{2} \mathrm{~S}$, mostrando também a superioridade do material amonizado (Tabela 5).

Ao utilizarem palha de arroz sem tratamento ou tratada com 3\% de uréia em dietas para novilhas com peso médio de 106 kg, Rahal et al. (1997) verificaram ingestão de matéria orgânica degradável, de 2,1 e 
2,6\% PV, respectivamente, para a palha não-tratada e tratada com $3 \%$ de uréia. Estes resultados foram semelhantes aos do presente trabalho, mostrando que a amonização aumentou o consumo, quando comparado ao material sem tratamento.

Apesar de não encontrarem diferença estatística no consumo de matéria seca, em função do peso metabólico, Neiva et al. (1998), trabalhando com novilhos de corte (peso médio de $337 \mathrm{~kg}$ ) alimentados com dietas à base de rolão de milho não-amonizado e amonizado com 2,4\% de $\mathrm{NH}_{3}$, encontraram valores de $89,45 \mathrm{gMS} / \mathrm{kg}^{0,75}$ para os animais que receberam o material não-tratado, elevando-se para 100,10 gMS $/ \mathrm{kg}^{0,75}$ para o rolão de milho tratado com 2,4\% de amônia anidra. Verificaram ainda que, ao submeterem silagens de milho contendo 35 e $45 \%$ de MS, amonizadas com $1,2 \%$ de $\mathrm{NH}_{3}$, também não se verificou diferença, observando-se consumos médios de 94,63 e 93,68 gMS/kg0,75.

Castrillo et al. (1995), em um experimento com ovinos alimentados com palha de cevada sem tratamento ou tratada com amônia anidra (3\% $\mathrm{NH}_{3}$ base MS), observaram aumento no consumo de palha (551 e $858 \mathrm{~g} /$ dia) e consumo de matéria seca, em função do peso metabólico (30,2 e 50,6 gMS/ $\left.\mathrm{kg}^{0,75}\right)$, para o material sem tratamento e o tratado com $\mathrm{NH}_{3}$. Estes resultados reforçam a melhoria da qualidade de forragens amonizadas e utilizadas na alimentação de ruminantes.

Verificou-se (Tabela 6) efeito dos tratamentos $(\mathrm{P}<0,01)$ sobre o consumo de fibra em detergente neutro, expresso em kg/dia (CFDND) e porcentagem do peso vivo (CFDNPV) e em função do peso metabólico (CFDNPM). Foram encontrados valores de 2,11; 2,46; 3,24; e 3,02 kg/dia para o CFDND, 0,84; 0,97; 1,17; e 1,14\% PV para CFDNPV e 33,37; 38,65; 47,61; e 46,14 gMS/kg0,75 para CFDNPM, respectivamente, para o tratamento controle, tratado com $\mathrm{Na}_{2} \mathrm{~S}$, tratado com $\mathrm{NH}_{3}$ e tratado com $\mathrm{NH}_{3}$ mais $\mathrm{Na}_{2} \mathrm{~S}$, os quais foram maiores para o bagaço de cana tratado com $\mathrm{NH}_{3}$, independentemente do $\mathrm{Na}_{2} \mathrm{~S}$. Isto se deve ao fato de o bagaço amonizado apresentar maior digestão da fração fibrosa, o que permite maior taxa de passagem.

O maior consumo de FDN (Tabela 6), em geral, para o material amonizado, pode ser atribuído ao

Tabela 5 - Consumo, ganho de peso e conversão alimentar de novilhas alimentadas com bagaço de cana-de-açúcar tratado ou não com amônia anidra $\left(\mathrm{NH}_{3}\right)$ e, ou, sulfeto de sódio $\left(\mathrm{Na}_{2} \mathrm{~S}\right)$

Table 5 - Intake, weight gain and alimentary conversion of heifers fed with sugarcane bagasse treated or not with anhydrous ammonia $\left(\mathrm{NH}_{3}\right)$ and, or, sodium sulphide $\left(\mathrm{Na}_{2} \mathrm{~S}\right)$

\begin{tabular}{|c|c|c|c|c|c|}
\hline \multirow[t]{2}{*}{$\begin{array}{l}\text { Variáveis } \\
\text { Variables }\end{array}$} & \multicolumn{4}{|c|}{$\begin{array}{l}\text { Tratamento (base da MS) } \\
\text { Treatment (DM basis) } \\
\end{array}$} & \multirow[t]{2}{*}{$\mathrm{CV}$} \\
\hline & $\begin{array}{l}\text { Controle } \\
\text { Control }\end{array}$ & $\mathrm{Na}_{2} \mathrm{~S}$ & $\mathrm{NH}_{3}$ & $\mathrm{Na}_{2} \mathrm{~S}+\mathrm{NH}_{3}$ & \\
\hline $\begin{array}{l}\text { Peso vivo inicial }(\mathrm{kg}) \\
\text { Initial live weight }(\mathrm{kg})\end{array}$ & 232,7 & 235,0 & 249,0 & 235,7 & - \\
\hline $\begin{array}{l}\text { Peso vivo final }(\mathrm{kg}) \\
\text { Finish live weight }(\mathrm{kg})\end{array}$ & 272,7 & 274,0 & 307,5 & 293,0 & - \\
\hline $\begin{array}{l}\text { Ganho de peso no período }(\mathrm{kg}) \\
\text { Weight gain period }(\mathrm{kg})\end{array}$ & $40,0 \mathrm{~b}$ & 39,0b & $58,5 a$ & 57,3a & 13,2 \\
\hline $\begin{array}{l}\text { Ganho de peso diário (g/dia) } \\
\text { Weight gain day (g/day) }\end{array}$ & $702 b$ & $684 \mathrm{~b}$ & 1026a & $1005 a$ & 13,3 \\
\hline $\begin{array}{l}\text { Consumo de MS (kg/dia) } \\
\text { Dry matter intake }(\mathrm{kg} / \text { day })\end{array}$ & $4,85 d$ & $5,24 \mathrm{c}$ & 6,81a & $6,38 b$ & 3,1 \\
\hline $\begin{array}{l}\text { Consumo de concentrado (kg MS/dia) } \\
\text { Concentrate intake ( } \mathrm{kgDM} / \text { day) }\end{array}$ & 3,04 & 3,04 & 3,04 & 3,04 & - \\
\hline $\begin{array}{l}\text { Consumo de volumoso (kg/dia) } \\
\text { Volumoso intake ( } \mathrm{kg} / \text { day) }\end{array}$ & $1,81 b$ & $2,44 b$ & $3,77 a$ & $3,34 a$ & 10,9 \\
\hline $\begin{array}{l}\text { Consumo de MS (\%PV) } \\
\text { Intake DM (\% } \% W)\end{array}$ & $1,92 b$ & $2,06 \mathrm{~b}$ & $2,46 a$ & $2,42 a$ & 3,9 \\
\hline $\begin{array}{l}\text { Consumo gMS } / \mathrm{kg}^{0,75} \\
\text { Intake } \mathrm{gDM} / \mathrm{kg}^{.75}\end{array}$ & $76,72 \mathrm{c}$ & $82,40 \mathrm{~b}$ & $100,18 a$ & $97,44 a$ & 2,6 \\
\hline $\begin{array}{l}\text { Conversão alimentar } \\
\text { Alimentary conversion }\end{array}$ & 7,26a & 7,73a & 6,69a & 6,33a & 16,5 \\
\hline
\end{tabular}

Médias seguidas das mesmas letras, na linha, não diferem $(P>0,05)$ pelo teste Tukey.

Means followed by the same letters, in a line, did not differ $(P>.05)$ by Tukey test.

R. Bras. Zootec., v.33, n.4, p.1078-1085, 2004 
ligeiro aumento no consumo de matéria seca (Tabela 5), em função da presença de maior umidade, apresentando mais concentrado aderido às sobras, comparado ao controle, que apresentou baixo teor de umidade e permitiu, dessa forma, que os animais selecionassem o concentrado, quando fornecido o bagaço sem amônia anidra.

Neiva et al. (1998) encontraram valores de consumo de FDN de 1,07 e 0,93\% do PV, ao alimentarem novilhos com rolão de milho sem tratamento e tratado com 2,4\% de $\mathrm{NH}_{3}$. Estes resultados, apesar de não apresentarem diferenças estatísticas, mostraram tendência de maior consumo de FDN para o material amonizado. Estes dados estão próximos aos encontrados no presente trabalho e podem ser explicados pela redução na fração da FDN, além do provável aumento da digestibilidade da mesma, o que foi relatado por Chermiti et al. (1994), ao trabalharem com palha de trigo tratada com uréia e amônia.

Verificou-se efeito $(\mathrm{P}<0,01)$ de tratamentos para os consumos diários de proteína bruta (CPBD), expressos em $\mathrm{kg} /$ dia e porcentagem do peso vivo (CPBPV), e para consumo de proteína bruta, em função do peso metabólico (CPBPM) (Tabela 6). Observou-se maior CPBD para as novilhas alimentadas com bagaço de cana tratado com amônia, enquanto os consumos para o bagaço sem tratamento e o tratado com sulfeto de sódio não diferiram entre si. Este comportamento foi semelhante para ambas as formas de expressar o consumo de PB. Os valores encontrados para CPBD foram de 0,62; 0,65; 1,24; e 1,23 , respectivamente, para os tratamentos controle, com $\mathrm{Na}_{2} \mathrm{~S}$, com $\mathrm{NH}_{3}$ e com $\mathrm{NH}_{3}$ mais $\mathrm{Na}_{2} \mathrm{~S}$.

Neiva et al. (1998) observaram consumo de 830 e 1100 g de PB/dia, ao alimentarem novilhos com rolão de milho não-amonizado e amonizado com 2,4\% de $\mathrm{NH}_{3}$. Os autores verificaram que a dieta rolão mais concentrado, para os animais alimentados com os respectivos tratamentos, continha 10,3 e 10,6\% de PB.

Os valores encontrados para CPBPV foram de 0,25; 0,45; 0,26; e 0,47\% PV e para CPBPM, de 9,87; 18,15; 10,17; e 18,80 g PB/ $\mathrm{kg}^{0,75}$ (Tabela 6).

$\mathrm{O}$ maior consumo de $\mathrm{PB}$ deve-se à presença do NNP adicionado pela amônia (82\% de N), que, mesmo após aeração, apresentou retenção média de $87 \%$. Apesar de recomendações de, no máximo, dois

Tabela 6 - Consumos de fibra em detergente neutro (FDN) e proteína bruta (PB) por novilhas alimentadas com dieta à base de bagaço de cana-de-açúcar tratado ou não com amônia anidra $\left(\mathrm{NH}_{3}\right)$ e, ou, sulfeto de sódio $\left(\mathrm{Na}_{2} \mathrm{~S}\right)$

Tabela 6 - Intake of neutral detergent fiber (NDF) and crude protein (CP) of heifers fed with sugarcane bagasse treated or not with anhydrous ammonia $\left(\mathrm{NH}_{3}\right)$ and, or, sodium sulphide $\left(\mathrm{Na}_{2} \mathrm{~S}\right)$

\begin{tabular}{|c|c|c|c|c|c|}
\hline \multirow[t]{2}{*}{$\begin{array}{l}\text { Itens } \\
\text { Items }\end{array}$} & \multicolumn{4}{|c|}{$\begin{array}{c}\text { Tratamento (base da MS) } \\
\text { Treatment (DM basis) }\end{array}$} & \multirow[t]{2}{*}{$\mathrm{CV}$} \\
\hline & $\begin{array}{c}\text { Controle } \\
\text { Control }\end{array}$ & $\begin{array}{l}\mathrm{Na}_{2} \mathrm{~S} \\
\mathrm{Na}_{2} \mathrm{~S} \\
\end{array}$ & $\begin{array}{l}\mathrm{NH}_{3} \\
\mathrm{NH}_{3} \\
\end{array}$ & $\begin{array}{l}\mathrm{Na}_{2} \mathrm{~S}+\mathrm{NH}_{3} \\
\mathrm{Na}_{2} \mathrm{~S}+\mathrm{NH}_{3} \\
\end{array}$ & \\
\hline \multicolumn{6}{|c|}{$\begin{array}{l}\text { Consumo }(\mathrm{kg} / \mathrm{dia}) \\
\text { Intake (kg/day) }\end{array}$} \\
\hline $\begin{array}{l}\text { FDN } \\
N D F\end{array}$ & $2,11 \mathrm{c}$ & $2,46 \mathrm{~b}$ & $3,24 a$ & $3,02 \mathrm{a}$ & 5,3 \\
\hline $\begin{array}{l}\mathrm{PB} \\
C P\end{array}$ & $0,62 \mathrm{~b}$ & $0,65 b$ & $1,24 \mathrm{a}$ & $1,23 \mathrm{a}$ & 3,1 \\
\hline \multicolumn{6}{|c|}{$\begin{array}{c}\text { Consumo }(\% \mathrm{PV}) \\
\text { Intake }(\% W L)\end{array}$} \\
\hline $\begin{array}{l}\text { FDN } \\
N D F\end{array}$ & $0,84 \mathrm{c}$ & $0,97 \mathrm{~b}$ & $1,17 \mathrm{a}$ & $1,14 \mathrm{a}$ & 3,6 \\
\hline $\begin{array}{l}\mathrm{PB} \\
C P\end{array}$ & $0,25 \mathrm{~b}$ & $0,26 \mathrm{~b}$ & $0,45 \mathrm{a}$ & $0,47 \mathrm{a}$ & 3,9 \\
\hline \multicolumn{6}{|c|}{$\begin{array}{l}\text { Consumo }\left(\mathrm{g} / \mathrm{kg}^{0,75}\right) \\
\text { Intake }\left(\mathrm{g} / \mathrm{kg}^{.75}\right)\end{array}$} \\
\hline $\begin{array}{l}\text { FDN } \\
N D F\end{array}$ & $33,37 c$ & $38,64 b$ & $47,61 \mathrm{a}$ & $46,14 \mathrm{a}$ & 3,2 \\
\hline $\begin{array}{l}\mathrm{PB} \\
\mathrm{CP}\end{array}$ & $9,87 b$ & $10,17 b$ & $18,15 a$ & $18,80 \mathrm{a}$ & 2,7 \\
\hline
\end{tabular}

Médias seguidas das mesmas letras, na linha, não diferem $(P>0,05)$ pelo teste Tukey.

Means followed by the same letters, in a line, did not differ $(P>.05)$ by Tukey test.

R. Bras. Zootec., v.33, n.4, p.1078-1085, 2004 
meses para o período de amonização, o período de 10 meses utilizado nesta pesquisa para o bagaço de cana-de-açúcar pode ter interferido na alta retenção de nitrogênio. Outro fato que também pode ter ocorrido foi o teor de umidade do bagaço de cana-de-açúcar tratado em torno de $50 \%$, o que também foi verificado em vários trabalhos de amonização, nos quais teores de umidade entre 30 e $50 \%$ se mostram mais eficientes.

\section{Conclusões}

O fornecimento de bagaço de cana-de-açúcar tratado com amônia anidra proporciona maior ganho de peso para novilhas em crescimento, comparado ao fornecimento de bagaço sem tratamento.

Maior consumo de MS, FDN e PB em kg/dia, em porcentagem do peso vivo e em função do peso metabólico, foi verificado para novilhas alimentadas com bagaço de cana-de-açúcar tratado com amônia anidra.

\section{Literatura Citada}

BÜRGI, R. Cana-de-açúcar. In: SIMPÓSIO DE NUTRIÇÃO DE PLANTAS, 6., 1995, Piracicaba. Anais... Piracicaba: Fundação de Estudos Agrários Luiz de Queiroz, 1995. p.153-70.

CASTRILLO, C.; FONDEVILA, M.; GUADA, J.A. et al. Effect of ammonia treatment and carbohydrate supplementation on the intake and digestibility of barley straw diets by sheep. Animal Feed Science and Technology, v.51, p.73-90, 1995.

CHERMITI, A.; TELLER, E.; VANBELLE, M. et al. Effect of ammonia or urea treatment of straw on chewing behaviour and ruminal digestion processes in non-lactating dairy cows. Animal Feed Science and Technology, v.47, p.41-51, 1994.

DJIBRILLOU, O.A.; PANDEY, V.S.; GOURO, S.A. et al. Effect of urea-treated or untreated straw with cotton seed on performances os lactating Marade (Red Sokoto) goas in Niger. Livestock Production Science, v.55, p.117-125, 1998.

FAHMY, S.T.M.; KLOPFENSTEIN, T.J. Treatment with different chemicals and their effects on the digestibility of maize stalks. 2. Intake and in vivo digestibility as affected by chemical treatment and monensin supplementation. Animal Feed Science and Technology, v.45, n.3/4, p.309-16, 1994.
FIKE, G.D.; SIMMS, D.D.; COCHRAN, R.C. et al. Protein supplementation of ammoniated wheat straw: effect on performance and forage utilization of beef cattle. Journal of Animal Science, v.73, p.1595-1601, 1995.

GARCIA, R.; NEIVA, J.N.M. Utilização da amonização na melhoria da qualidade de volumosos para ruminantes. SIMPÓSIO NORDESTINO DE ALIMENTAÇÃO DE RUMINANTES, 1994, Salvador. Anais... Salvador: 1994. p.41-57.

GOONEWARDENE, L.A.; SPICER, H.M.; ENGSTROM, D.F. et al. A study on feeding ammoniated and processed barley to feedlot steers. Animal Feed Science and Technology, v.74, p.135-142, 1998.

NEIVA, J.N.M.; GARCIA, R.; VALADARES FILHO, S.C. et al. Desempenho de bovinos de corte alimentados com dietas à base de silagens e rolão de milho amonizados. Revista Brasileira de Zootecnia, v.27, n.3, p.466-473, 1998.

NATIONAL RESEARCH COUNCIL - NRC. Nutrient requirements of dairy cattle. 6.ed. Washington, D.C.: National Academy Press, 1989.

OLIVEIRA, E.R.; LIMA, J.O.A.A.; ALMEIDA, S.A. et al. Desempenho de novilhos de corte alimentados com palha de arroz amonizada e não amonizada. In: SIMPÓSIO NORDESTINO DE ALIMENTAÇÃO DE RUMINANTES, 5., 1994, Salvador. Anais... Salvador: Sociedade Brasileira de Zootecnia, 1994. p.198-202.

RAHAL, A.; SINGH, A.; SINGH, M. Effect of urea treatment and composition on, and prediction of value of rice straw of different cultivars. Animal Feed Science and Technology, v.68, p.165-182, 1997.

REIS, R.A.; RODRIGUES, L.R.A. Amonização de volumosos. Jaboticabal: Universidade Estadual Paulista, 1993. 22p.

SILVA, D.J. Análise de alimentos: métodos químicos e biológicos. Viçosa, MG: Universidade Federal de Viçosa, 1990. 165p.

UNIVERSIDADE FEDERAL DE VIÇOSA - UFV. SAEG Sistema de análises estatísticas e genéticas. Versão 8.0. Viçosa, MG., 1998 (Apostila).

Recebido em: 20/05/02 Aceito em: 14/10/03 